Turning now to Dundce, abservations there show that the baxometer fell very fast till about 7 P.M., after which it remained nearly stationary for about two hours; at 7.15 the Tay Bridge was blown down; about 7.45 the actual trough of the cyclone passed over the town, and about 9.3० P.M. the barometer began to rise. The wind, which had been strong all day, rose to a strong gale with violent gusts and squalls at 5 P.M., and lasted till 8.30, when the weather began to moderate.

Thus it would appear that in this storm at Dundee, as is often the case, the worst weather occurred just before the barometer ceased to fall, and during the two hours it remained nearly stationary previously to rising rapidly. The Tay Bridge was blown down by an ordinary gust during this time, and not in any squall during the time of the actual passage of the cyclone's trough.

On the whole it may be said that though the storm which destroyed the Tay Bridge was in many ways of the most ordinary character, it was exceptionally squally and gusty, doubtless owing to the unusually rapid rate of its motion.

One word in conclusion, as to the destructive effect of wind. A gust strikes with a blow, which can no more be calculated from the velocity of the wind, than the blow of a sledge-hammer can be estimated by a pressure in tons, or by the energy of so much momentum. But observation also shows that in squalls and gusts there is a great deal of local compression of the air; fluid pressure must then come into play, and in this we have, probably, the explanation of the remarkable lifting power of wind, which has been so often described in great storms. Unfortunately in our present state of knowledge, this lifting force is as incapable of numerical estimation as the lateral blow of the gusts.

My acknowledgments are due to Dr. Copeland for his courtesy in furnishing me with copies of the meteorological records of the Dunecht Observatory, situated about fifty-six miles north-northeast of Dundee.

7, Royal Terrace, Folkestone

\section{A Lecture Experiment on Ice-Crystals}

THOUGH different processes are at command on the lecturer's cable to illustrate the artificial formation of ice, none of them may be said to yield the very forms of ice-crystals that are observed in snow-figures or in hoar-frost. I have hit upon a method for producing them in an equally simple and satisfactory way. If a glass tube (with a length of one or two decim. and four or five millim. wide) has by means of the blowpipe one of its ends reduced to a diameter of two millim., some fibrous matter, as loose cotton-wool or gun-cotton, \&c., must be introduced into this part, in such a way that many single fibres protrude out of the tube. They form the lower part when the tube is now fixed in a vertical position, and some sulphuric ether dropped in tbrough the upper end in sufficient quantity to keep the fibrous substance moist, but not enough to run over. An aciive evaporation favoured by a comparatively large surface and the radiation from a multitude of points, sets in immediately, and within a minute ice-crystals, as a deposit from the atmospheric moisture, are seen growing in all directions on the fibres, imitating exactly the snow-figures. If very small quantities of ether are now continually supplied, a group of crystals and needles, sometimes to a length of two centim., is readily obtained, affording, when projected on a screen, a very elegant experiment which is rapidly going on and is successful even at a surrounding temperature of $13^{\circ} \mathrm{C}$.

The way by which these crystals are here obtained may elucidate the question on the formation of the ice-crystals observed by the Duke of Argyll and recently discussed in Nature. I think that the ligneous substance, from its rotten condition, pre. sents an innumerable quantity of very thin fibres, cooling after sunset rapidly by radiation, and their surfaces, getting to a ter perature beneath the freezing-point, cause the vapour of water, with which the surrounding atmosphere becomes now surcharged, to be slowly deposited in the crystallised form exactly as in the above experiment. The crystals, ending in needles and sharp points, continue to cool by radiation, and therefore increase at their extremities, till their length is stfficient to have gravity exerting its influence in curling them round the bark.

The Hague, Holland, March

$$
\text { L. BLEEKRODE }
$$

\section{Cloud Classification}

THOSE who have long taken an interest in the subject of the classification of the clouds, will heartily congratulate themselves that this study is again resuming a fair share of the attention of meteorologists, and is likely to be more fully discussed than it has been for many years.

Luke Howard's Classification was, as far as he knew at the time, a first attempt to introduce order into fields of observation, then almost untried by scientific men. No one could suppose that it would at once exhaust the whole subject and be incapable of either extension or modification by later observers who possess the advantage of a much more mature stage of the science of meteorology. Still I may be allowed, without prejudging the result of the present discussion, to suggest one or two practical cautions to those who may be taking the subject in hand.

Firstly-Luke Howard's nomenclature of clouds has, since his time, been passed from hand to hand by a great number of observers, many of whom have apparently never taken much trouble to ascertain what he really intended to define by certain names, or what were the principles on which the classification was based. Therefore, before too readily finding fault either with the names or the original application of them, it might be well to give somewhat thoughtful study to the very carefully worded descriptions and definitions in Luke Howard's own work on the subject. 1

Secondly-Clouds are by their very nature liable to frequent. changes from one class to another, during which they must pass, more or less rapidly, through intermediate forms. If an attempt is made to classify all these temporary and intermediate varieties, the science will become rather unusually complicated. Were the same principle carried out in other branches of observation we should, for example, have to classify the tadpole as an important separate variety of the batrachians.

In conclusion I may remind the observer of the advice of Goethe in his remarks about Howard's nomenclature -which advice is as applicable now as when it was first written-" Not to allow himself to be led astray by the occurrence of certain indistinct appearances, but to practice himself in referring the same to the main rules (or classes) under which they come."

Walthamstow, March

ELIOT HOWARD

\section{Diatoms in the London Clay}

Since you were good enough to allow me to announce in NATURF, the discovery of diatoms in the London clay, I have been able to trace the band in which they occur throughout the whole extent of the London clay in East Kent-and at one spot in Mid-Kent. In continuing the inquiry, with vol. iv. of the Memoirs of the Geological Survey for my guide, I have found that sections that were visible when that valuable work was published are now overgrown or have been removed. Under these circumstances will you allow me to ask your readers for information as to places where tolerably fresh sections of the lower part of the London clay can be seen, especially at or near the northern and the western outcrop of the formation?

As regards the eastern part of Kent, the investigation is complete, and therefore no correspondence need take place respecting sections in that district.

Also I should like to have information as to any wells in course of being sunk in any part of the London basin.

I may observe that I have invariably found these fossil diatoms only in clay of a uniform dark slate colour, that dries out dark grey, and has a tendency to lamination.

On splitting open a fresh piece of clay, the diatoms, if present, are easily seen with the help of a pocket lens, as shining specks, and if plentiful their metallic lustre is evident to the unassisted eye.

W. H. ShrubSOLE

\section{Meteor}

YESTERDAY evening, when observing the zodiacal light, in order to get its limits among the stars, I remarked a fire-ball in the same direction, which may have been perceived also in England, where it was seen, perhaps, near the zenith. I give you the elements of my observation to be published in your journal.

Mean local time 7 h. 2om. evening, March 3.

Direction of the apparent path from the width of the arc $\mu-\xi_{2}$ Ceti towards the width of the arc $\gamma$ Ceti $-\alpha$ Piscium.

The beginning was very small, but towards the end the brightness increased very quickly, and the phenomenon ended 1 Essay on the Modifications of Clouds, by Luke Howard, F.R.S. Third dition, with plates. (Churchill, 1865 .)

2 Quoted in preface to third edition of the essay, \&c. 